\title{
KARL-ERIK FORSSLUND - PIONJÄR INOM HEMBYGDSVÅRDEN
}

\author{
Göran Rosander
}

I dag är det inte särskilt många svenskar som känner till Karl-Erik Forsslund. Ändå var han en av det börjande 1900-talets stora svenska kulturpersonligheter, framför allt bekant som skald och kulturhistorisk författare. Än mindre känd torde han vara $i$ utlandet; blott två hans skrifter är översatta till annat nordiskt språk.

Forsslund hade också andra intressen, och det är de som gör det berättigat att àterge en av hans texter i tidskriften. Han var en av de tidigaste förespråkarna for naturvård och kulturvard i Sverige, och med hjälp av hans position och engagemang blev boken Hembygdsvård (1914) en väckarklocka; 1916 grundades t.ex. Samfundet för hembygsvard (nu: Sveriges hembygdsforbund). Forsslund var dessutom praktiskt engagerad $i$ museiverksambet på lokalplanet samt bedrev en dokumentation av hemprovinsendet största etnologiska fältarbete som någonsin lagts upp i Sverige.

På en udde i Väsman utanför Ludvika i Dalarna ligger Karl-Erik och Fejan Forsslunds röda bergsmansgård, Storgården. Den blev inköpt av hans svärfar brukspatronen till det unga parets bröllop 1898, och där bodde Forsslund till sin död 1941.

Storgården intar en remarkabel plats inom många sektorer av svensk kulturhistoria. Namnet återfinns på en bok från år 1900, en skrift som blev en kultbok för en hel generation. Färgen anses ha bidragit till falu rödfärgs renässans, drömmen om «den röda stugan». Interiören blev förebild för den radikala, intellektuella samtidsge- nerationen, man kan kalla den «folkbildaridealisterna». Gården blev träffpunkt för den socialdemokratiska ungdomen från den närbelägna folkhögskolan. Till Storgården drog halva svenska intelligentian för att träffa Forsslunds. Gården kom att fungera som replipunkt och viloställe för Karl-Erik, Vandraren i svensk litteratur, med en väntande, förståelsefull hustru trots vissa antydningar till utbrytningar. Och här i Bokstugan tillkom bok efter bok, förutom tillfällighetsvers, föredragsmanus, tidningsartiklar, insändare, recensioner och översättningar - Forsslund var arbetsnarkoman. 
118 Karl-Erik Forsslund föddes 1872 i Västmanland. Han var brådmogen: student vid knappa 17 år, första publicerade dikt vid 18 , bokdebut vid 24, fil. lic. i Uppsala vid 25, därefter skribent i skämtbladet Strix i Stockholm, nystartat av den några år äldre Albert Engström. Forsslund trivdes emellertid inte. Staden föreföll honom som ett fängelse, och när möjligheten öppnades att slå sig ned på landet som fri litteratör då Storgården inköptes, grep han chansen.

Avskyn mot livet i staden, samman med kärleken till hustrun och glädjen över att få leva ett frustande, fritt liv i lantlig miljö resulterade i Storgården, en idéroman, bestående av en märklig blandning av självbiografiska inslag från hans förälskelse i hustrun, programskrift för «naturliv» samt fiktion, med insprängda dikter. Boken nådde nio upplagor på 28 år (samt facsimilutgåva 1991) - en av sin tids stora succéer.

\section{FÖRFATTARSKAP}

Framgången med Storgården upprepades inte, trots ett flitigt författarskap inom många genrer.

Först skönlitteratur. Från hans hand kom en strid ström av fiktion: flera skådespel, novellsamlingar, romaner, samlingar av skisser, berättelser och historier, en och annan barnbok och, framför allt, diktsamlingar. Åtskilliga dikter har tonsatts och återfanns ganska länge t.ex. i folkhögskolornas sångböcker. Det mesta är $\mathrm{i}$ dag stendött, vilket också gäller prosatexterna. I dag lever väl bara visorna Vägarna de skrida och Kullerullvisan.

Ett par av böckerna har visst intresse, genom att den fogar sig in i Forsslunds vandrings-»tvång» och $\mathrm{i}$ hans intresse för orörd natur. Den ena är diktsamlingen Till fjälls (1911) och har som motiv fjällnaturen och samerna, den andra är prosaboken Som gäst hos fjällfolket. Samen stod vid denna tid i centrum för flera radikala debattörers intresse och sågs som en oförfalskad människa, "fri, frisk och frejdig" (Forsslund). Fjällfolket blev brickor $i$ en civilisationskritik: man såg dem som en hotad, förnedrad och orättvist behandlad folkspillra under industrikapitalismen.

En helt annan dignitet har Forsslunds kulturhistoriska författarskap, då inte artiklar och uppsatser, men hans magnum opus Med Dalälven från källorna till havet, som blivit kallat "ett litterärt landskapsmuseum». I drygt 20 år vandrade han nästan varje sommar genom ett stycke Dalarna, börjande längst upp i nordväst. Under perioden 1918 till 1939 utgav han 27 häften i stort format på tillsammans 5500 sidor och hann fullfölja områdena längs Österdalälven, Västerdalälven och de förenade älvarna ned t.o.m. Falun. Böckerna är fyllda av beskrivningar av topografi och natur samt iakttagelser av och framintervjuade fakta om miljöer och folkkultur, främst byggnadsskick, dräktskick, historiska minnen, sedvänjor, bruk, sägner och folkmusik. Boken illustreras med ca 5000 foton, varav han själv tagit $60 \%$; Forsslund insåg tidigt fotots betydelse och har efterlämnat sig ca 13000 bilder. Ingen tillnärmelsevis motsvarighet finns på svensk botten, och verket är av oskattbart värde.

\section{FOLKBILDAREN}

Det fanns allid hos Forsslund en lust att missionera, att gå i spetsen som förebild, 
att belära och sprida kunskap. Redan Storgården gör han sig som nämnts till talesman för en lantlivets och sundhetens ideologi.

En handfast folkbildaruppgift väntade. 1900-talets första årtionde var en tid för grundandet av folkhögskolor i landskapet.
Forsslund jämte två kamrater beslöt 1906, i hastigt mod får man nog säga, att också de skulle starta en folkhögskola, då med arbetarrörelsens ungdomar som speciell målgrupp. Platsen blev Brunnsvik, dvs. den lilla ort där Storgården ligger. Skolan kom igång samma höst men mötte på

Karl-Erik Forsslund (1872-1941) spelar spillapipa på gårdstunet vid Ankarcronas gård Holen $i$ Tällberg. Foto i Dalarnas museums arkiv.

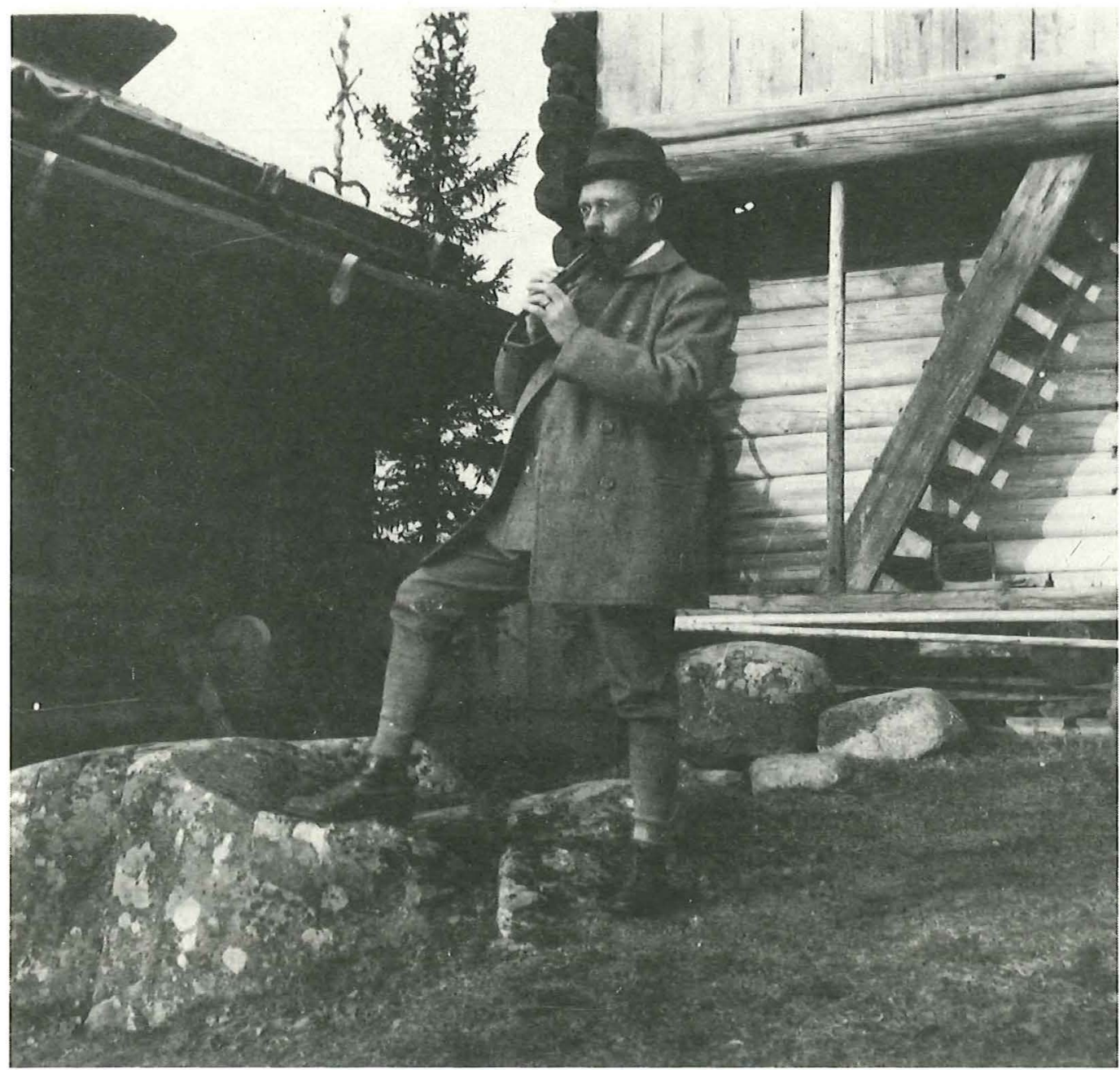




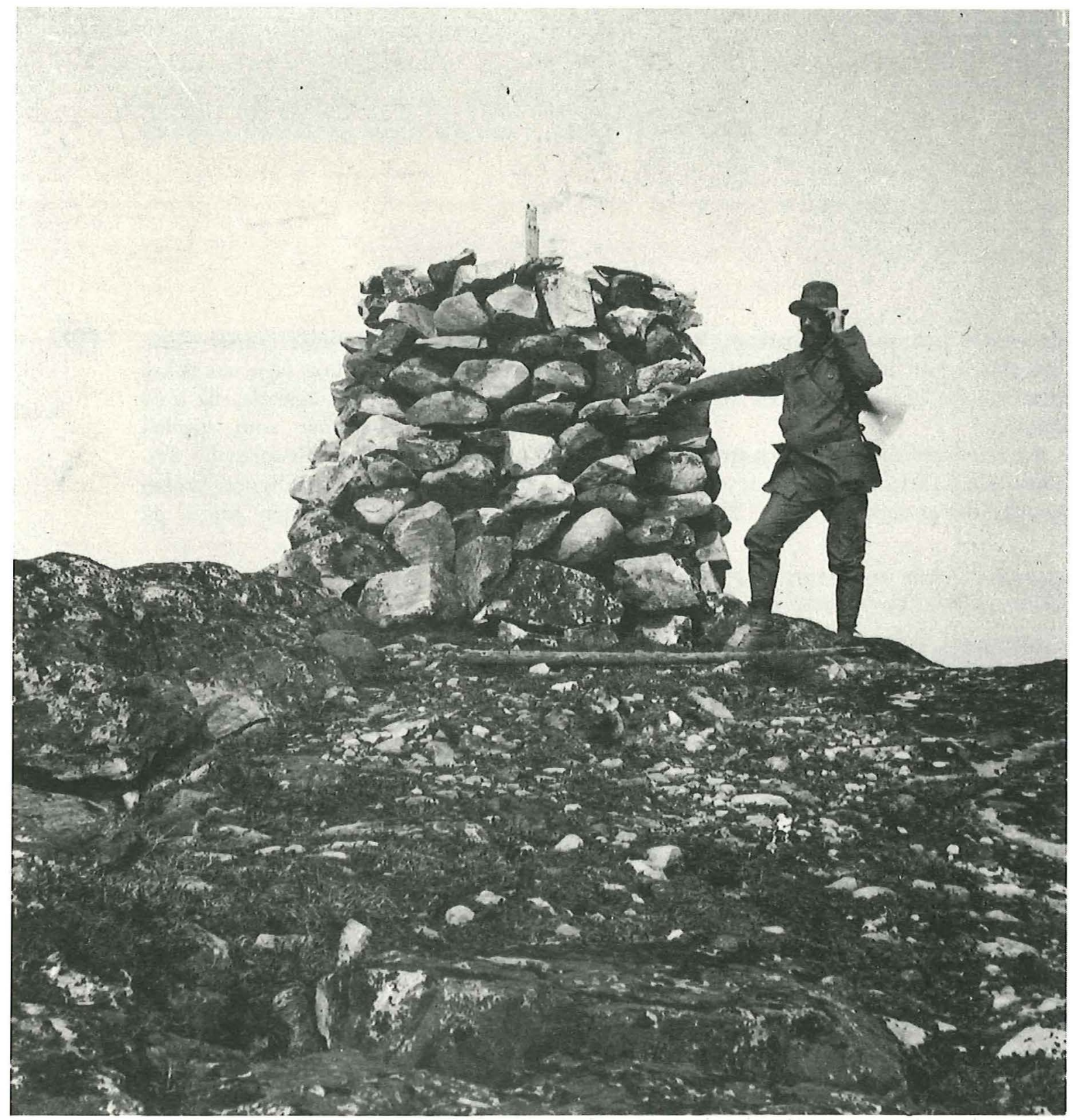

Karl-Erik Forsslund på Dalarnas högsta punkt, Storvätteshågna.

Foto i Dalarnas museums arkiv.

grund av sin inriktning motgångar då det gällde att få kommunala anslag. Forsslund svarade för delar av undervisningen, bl.a. i astronomi, natur- och hembygdskunskap samt filosofi. Sedan skolans föreståndare avgått 1907, tvangs Forsslund att ta på sig ansvaret med tillhörande administration, något som blev ett tvång, och 1912 sade han upp sig. - Brunnsvik har förblivit arbetarrörelsens folkhögskola, där en mycket stor del av den första generationens politiska och kulturella elit passerat som elever eller som lärare.

Efter att lönen från skolan upphört, måste Forsslund skaffa inkomster från annat håll. De ojämna inkomsterna från skriftställeriet räckte inte - han slogs hela livet mot dålig ekonomi. Utvägen blev föredragsturnéer. Under några år for han land och rike runt och föreläste; han hade en lista på några tiotals ämnen som arrangörerna kunde välja från. Resandet blev 
dock slitsamt, och han tvangs upphöra med föreläsning som profession. På hembygdsdagar och i liknande sammanhang framträdde han dock även i fortsättningen.

\section{POLEMIKERN}

Forsslund älskade att stå på på barrikaderna och kom ofta i polemik med oliktänkande. Hans radikala tankegångar och liering med arbetarrörelsen skapade, som vi hört, konflikter md etablissemanget. Som naturälskare var Forsslund djupt engagerad också i djurskyddet, och flera gånger råkade han $\mathrm{i}$ insändardiskussioner kring hotad fauna. Han skrev även ilskna artiklar om hotad natur och kultur, nybyggnader och rivningar, böcker som han inte gillade innehållet $\mathrm{i}$ samt om språkliga inadvertenser

Viktigare var emellertid hans strid mot det han uppfattade som dålig, artfrämmande arkitektur. Självklart drog han i härnad mot Stockholmsutställningen 1930 och dess funkishus. Kritiken framfördes bl.a. i åtskilliga föredrag vid hembygdsmöten under sommaren. På hösten blev Kooperativa Förbundet hans motståndare; KFs varuhus ritades vid denna tid i funkis. Forsslund gick i flera artiklar till storms i förbundets tidskrift. Den vidare polemiken hade flera inslag och slutade snarast med att Forsslund fick stämpel på sig som som bakåtsträvare.

\section{STORGARDEN SOM KULTURMILJÖ}

Det forsslundska hemmet fick, som antytts, mängder av besök - också av nyfikna, oinbjudna människor. Folkhögskolans elever inbjöds till musikaftnar -
Fejan var utbildad på Musikaliska Akademien, och även Karl-Erik var mycket musikalisk och komponerade en del. Eleverna fick också låna böcker ur det rikhaltiga biblioteket. Den stora bekantskapskretsen, med representanter för det litterära, konstnärliga och politiska etablissemanget, inviterades ofta.

Det finns starka skäl att stanna för en av dessa: Ellen Key (1849-1926), kulturradikal och på sin tid en av de stora namnen inom den europeiska intelligentian. Hennes skrifter avhandlar bl.a. moral, estetik, kvinnosaksfrågor, pacifism samt barnens rätt. De har översatts till många språk. En av hennes kungstankar gällde folkbildningen, en annan hemmet som institution. Det fanns enligt henne en stark moralisk och emotionell dimension i hemmets utformning; denna skulle höja den fysiska och psykiska livskänslan. Ett vackert hem skapar lyckliga och harmoniska människor. Ellen Key ville t.o.m. se hela samhället som ett hem.

Tankegångarna delades av Forsslunds. Storgården och dess inredning hade redan genom boken med samma namn blivit symbol för en ny livsstil - en äktsvensk stugtrevnad i estetisk och intellektuell tappning. Undertiteln var just En bok om ett hem. I senare skönlitterära böcker och i sina föredrag och föreläsningar återkommer Forsslund gång på gång $\mathrm{i}$ text och bild till sitt eget hem som mönster. Tidningsreportage förstärkte spridningen, "hela Sverige» visste hur Forsslunds hade det hemma. Storgårdens stil, inte minst färgsättningen, var, sannolikt genom Ellen Keys förmedling, påverkad av Carl Larsson samt av de engelska idealen i The Studio och hade också vissa inslag från interiörerna i Bergslagens herrgårdar. 
122 Framför allt blev det den trivsamma övre salen på Storgården som alla föll för. Där fanns inte minst den berömda «latbänken», efterbildad i tusen hem: en schäslong med en hylla med böcker ovanför.

Hemmet blev ett av ledmotiven, kanske det viktigaste, i Forsslunds hela gärning.

\section{HEMBYGDSVARDAREN OCH MUSEIMANNEN}

Storgården innehöll ett anatema över storstaden med dess trånga gator och bolmande industrier. Mötet med allmogekulturen och naturen i Dalarna innebar ett incitament till Forsslunds kommande, hembygdsvårdande gärning. Kontakten med Ellen Key, målaren och hembygdskämpen Gustaf Ankarcrona i Leksand samt arkitekten John Åkerlund, som studerat och inspirerats av allmogearkitekturen, gav ytterligare tankar, liksom de stora dalska idealistiska ungdomsmötena under seklets första decennium. Hembygdsgårdar hade också börjat grundas i landskapet vid samma tid. År 1909 hade riksdagen fattat beslut om att inrätta nationalparker och infört en lag om fredandet av naturminnesmärken. Året därpå grundades Svenska naturskyddsföreningen.

Forsslund hade nu laddat upp, och 1914 kom den märkliga bok som heter Hembygdsvård. Den består av två delar: "Naturskydd och nationalparker» och "Kulturskydd och bygdemuséer». Typiskt för Forsslund är sammankopplandet av natur och kultur. I en medryckande text, förstärkt av många bilder, går Forsslund till storms mot kraftverksbyggenas och storindustrins negativa följder: forsars utplånande, översvämningar, skövlade skogar och annan natur, försämrat fiske, förpestad luft. Ny, oskön arkitektur i tätorterna - särskilt hatade han stationssamhällenas vildvuxna, brackiga bebyggelse - får en bredsida. Också den enligt Forsslund plottriga inredningen i många hem blir kritiserad. Mot dessa "hemskheter» ställer han den traditionella kulturen, och han talar sig varm för museitanken för att bevara det gamla - men inte i de stora, centrala museerna utan i lokala museer och hembygdsgårdar. Centralmuseernas inventarium bör återföras till resp. hemort - en tankegång som delvis återkommer $\mathrm{i}$ 1994 års museiutredning. Allra helst bör man avtala med folk att behålla sina gamla ting - alltså ekomuseets idé. Forsslund är som synes förbluffande modern i sitt tänkande.

Ännu en bok med naturvård som tema är Fridlysta vildmarker (1915), som består av reportage från olika nationalparker. Naturskildringarna är ofta «lyriska och rytmiska i uppenbart syfte att förmedla vandrarens naturglädje till läsaren» (Furuland).

Nyssnämnda år var Forsslund med om att grunda Dalarnas Hembygdsförbund, en sammanslutning av hembygdsföreningar och enskilda medlemmar, den första av sitt slag i landet. Dylika sammanslutningar hade han propagerat för i Hembygdsvård. Han blev förbundets sekreterare och redaktör och nedlade stort arbete på uppgiften, som även innefattande räddningen av naturminnen.

Självklart var Forsslund också med om starten av Ludvikabygdens Fornminnesoch hembygdsförening och blev dess ordförande. För Ludvika gammelgård (1924) gjorde han en stor insats som insamlare och "museilärare", inte minst för folkhögskoleeleverna. Han hann också uppleva att 


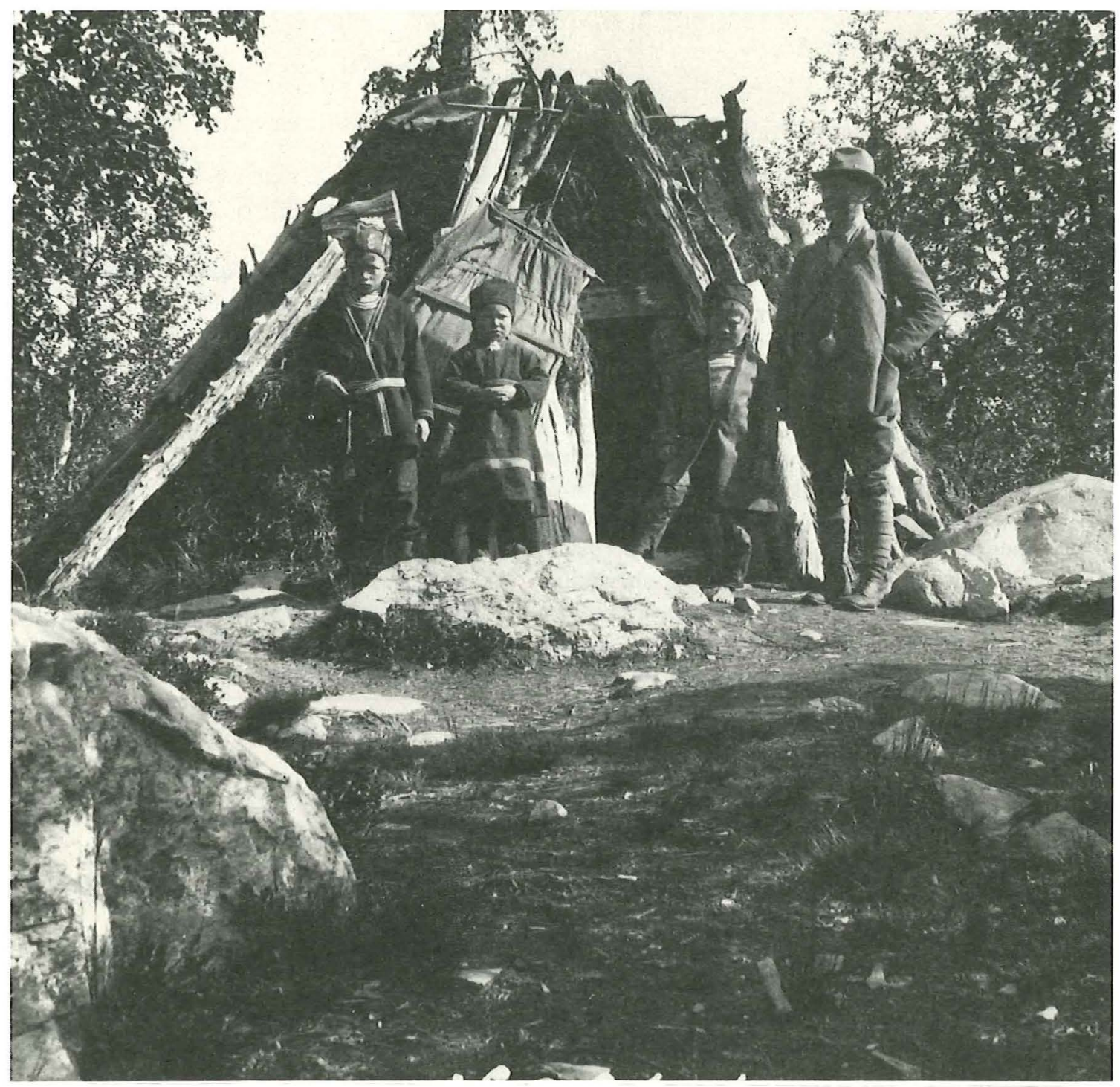

Karl-Erik Forsslund utvecklade en fotografisk metodik med en enkel Kodak-kamera av rullfilmtyp frän 1905.

Bilden efter Forsslunds besök hos Idre-samer framför skolkåtan vid Töfsingsjön publicerades $i$ den första Dalaälusboken, Storån. Foto: Karl-Erik Forsslund, i Dalarnas museums arkiv.

gammelgården kompletterades med världens första frilufts-gruvmuseum (1938), med en rad flyttade maskiner och anläggningar.

Det utdrag ur Hembygdsvård som återges som «klassikern» utgör slutkapitlen av boken. Texten, som i original är rikt illustrerad, har förkortats ganska kraftigt. Förutom sitt betydande ideologiska och idéhistoriska intresse är texten viktig som historiskt dokument över hembygdsrörelsens inspiration från Finland och framför allt Tyskland. Det kan nämnas att första gången ordet hembygdsförening dyker upp tycks vara i Lojo i Österbotten, där en sådan bildades 1894. I Sverige blev 'hembygd' och 'hembygdsrörelse' använt från ungefär 1903-1904, enligt vad skalden och hembygdsentusiasten Carl Larsson i By uppgivit. 
SUMMARY

Karl-Erik Forsslund, a pioneer

in the preservation of local monuments

Karl-Erik Forsslund (1872-1941) was in his day a prominent figure in Swedish public life. Nowadays he is almost forgotten. He was a poet, a journalist and a novelist, dedicated all his life to the study of cultural history. He participated eagerly in public education and the maintenance of monuments. From 1898, when he married, until he died he lived in a traditional farmhouse, Storgarden, close to Ludvika in Dalecarlia. Storgarden was also the title of his most successful book, which appeared in 1900 , a remarkable pamphlet idealizing life in the countryside. Nine editions were printed and it became a cult book for radical intellectuals at the turn of the century. On their farm Forsslund and his wife received a stream of visitors prominent in the literary and political establishment of the day. His home, Storgården, became a permanent point of reference in his writings, he loved the place and made home a central concept in his literary work. Again and again he used the interior of his own home as the model for what a living home should look like.

The only work by Forsslund which is still read is the unfinished description of the valley of the river Dalälven ('Med Dalälven från källorna till havet'), on which he worked from 1918 to 1939 . He had difficulties financing its publication, nevertheless 27 volumes, comprising 5.500 pages, appeared. It is a profusely illustrated topographical and historical account of this central part of the province of Dalecarlia.

In the field of antiquarian work he was remarkably modern. In the book $O n$ the preservation of local monuments ('Hembygdsvård', 1914) divided into two parts, the first dealing with the preservation of nature, the second dealing with the care of local culture he launches an anathema over the ruin of the former and the devastating effect of modernization on the cultivated land.

The part of this book which is reprinted here is from its last pages and expresses his opinions about the function and mission of national and local museums.

\section{LITTERATUR}

Göran Rosander (red.): Karl-Erik Forsslund. Författaren, folkbildaren, hembygdsvårdaren. Hedemora 1991. (Även i: Dalarnas

Hembygdsbok 1991.) 